\title{
Caracterização de efluente de lagoa anaeróbia da cidade de Franca - SP para estudo de desinfetante alternativo visando o uso na agricultura ANAEROBIC POND EFFLUENT CARACTERIZATION FROM FRANCA CITY - SP - TO STUDY AN ALTERNATIVE DESINFECTANT AMING THE AGRICULTURAL USE
}

\begin{abstract}
Daniele Tonon ${ }^{(1)}$
Bruno Coraucci Filho(2)

Luana Mattos de Oliveira Cruz ${ }^{(3)}$

Regiane Aparecida Guadagnini( ${ }^{(4)}$

Warner Arantes Zebalho ${ }^{(1)}$
\end{abstract}

(1)Química pela Universidade Estadual Paulista - UNESP e doutoranda em Saneamento e Ambiente pela Faculdade de Engenharia Civil, Arquitetura e Urbanismo - UNICAMP (2)Professor Titular da Faculdade de Engenharia Civil, Arquitetura e Urbanismo - UNICAMP

(3)Doutoranda em Saneamento e Ambiente pela Faculdade de Engenharia Civil, Arquitetura e Urbanismo - UNICAMP

(4)Mestranda em Saneamento e Ambiente pela Faculdade de Engenharia Civil, Arquitetura e Urbanismo - UNICAMP (5)Graduando em Tecnologia em Saneamento Ambiental pelo CESET - UNICAMP.

Endereço: Faculdade de Engenharia Civil, Arquitetura e Urbanismo. FEC/UNICAMP; Avenida Albert Einstein, 951; Cidade Universitária "Zeferino Vaz"; Caixa Postal 6021; CEP: 13083852; Campinas - SP. Telefone: 19-3788-2381. E-mail: daniele_tonon2005@yahoo.com.br

fecção de efluentes de uma lagoa anaeróbia, situada em Franca, SP e administrada pela Sabesp. Na desinfecção variou-se os tempos de contato em 30 , 45 e 60 minutos. Dosagens entre 25 e $32 \mathrm{mg} \mathrm{L}^{-1}$ foram necessárias para adequar o efluente aos padrões estabelecidos pela OMS (1989) e pelo CONAMA 357/05 para reuso em culturas agrícolas $e$ padrões de lançamento em corpos receptores - $E$. coli < 103 NMP $100 \mathrm{~mL}^{-1}$ e Helmintos $<1$ ovo $\mathrm{L}^{-1}$.

\section{ABSTRACT}

Wastewater disinfection, not only to attend the discharge into receiving waters patterns but also to for the agriculture reuse, is an indispensable treatment process to the public health protection. In this investigation the Calcium Hypochlorite is shown as a disinfectant, because, one of the great advantages from this technique is that there is residual chlorine in contact with the effluents which is able to eliminate organisms that cause the mainly water-borne diseases. General aim of this study is the disinfection evaluation of an anaerobic pond effluent, located in Franca city, SP and managed by Sabesp (São Paulo State Basic Sanitary Company). In the disinfection, contact times were varied in 30, 45 and 60 minutes. Dosages between 25 to $32 \mathrm{mg} \mathrm{L}^{-1}$ were

\section{RESUMO}

A desinfecção de águas residuárias, tanto para atender a padrões de lançamento em corpos receptores quanto para o reúso agrícola, é um processo de tratamento indispensável à proteção da saúde publica. Neste trabalho o hipoclorito de cálcio é apresentado como desinfetante, pois, uma das grandes vantagens desta técnica é que há um residual de cloro em contato com os efluentes capaz de eliminar os organismos causadores das principais doenças de veiculação hídrica. $O$ objetivo geral deste trabalho é a avaliação da desin'essary to adapt effluent to patterns stablished by WHO (1989) and by CONAMA 357/05 for the agriculture reuse and to the discharge into receiving waters - E. coli < $103 \mathrm{NMP} 100 \mathrm{~mL}^{-1}$ and helminths $<1$ ovo $L^{-1}$.

Palavras-chave: desinfecção; reúso; hipoclorito de cálcio; efluente de lagoa anaeróbia.

Keywords: disinfection, reuse, Calcium Hypochlorite, anaerobic pond effluent. 


\section{INTRODUÇÃO}

Levando-se em consideração a estimativa feita pela Organização Mundial de Saúde (OMS) que em torno de 2025 a população mundial será de 8.9 bilhões e será a máxima que o suprimento de água na terra pode suportar. Algumas providências devem ser tomadas no sentido de minimizar o problema da escassez tornando-se necessário o estudo de técnicas alternativas para a minimização deste problema.

A desinfecção de efluentes sanitários para o uso na agricultura é uma boa alternativa encontrada para diminuir a demanda de água potável utilizada na irrigação, pois, de acordo com ANA (2003), no Brasil a irrigação consome cerca de $60 \%$ de água potável do país, o que não é diferente da demanda global que corresponde a $70 \%$ de toda a água consumida no planeta (FAO, 2002).

A maioria absoluta das Estações de Tratamento de Esgoto (ETE) no Brasil não possui uma etapa específica para a desinfecção. O tratamento de água e esgotos, entretanto, implica na utilização de substâncias químicas que podem, por sua vez, afetar a saúde daqueles que a utilizam.

A cloração seguramente é a técnica mais empregada, pois, em qualquer dos seus diversos compostos, destrói ou inativa os organismos causadores de enfermidades, sendo que esta ação se dá à temperatura ambiente e em tempo relativamente curto (MEYER et al (1994) e TOMINAGA (1999)). E também, levando-se em consideração que ao final do processo deixa um residual de cloro na rede, item muito importante para a saúde pública, pois, este controle é obrigatório em todas as estações de água para abastecimento público. Os demais reagentes não possuem esta característica e além do mais, não se tem estudos conclusivos com relação à formação de subprodutos da desinfecção. Sua aplicação é simples exigindo equipamentos de baixo custo.

Foi escolhido um desinfetante alternativo para este trabalho, o hipoclorito de cálcio, que possui característica diferente ao do hipoclorito de sódio, este, muito utilizado em estações de tratamento de água (ETA). De acordo com Hotta (2009) um dos grandes problemas na agricultura mundial é a salinização dos solos. Os agricultures irrigam suas plantas o tempo todo, a água evapora e o sal da água acumula-se nas plantas. De modo geral, plantas são bastante sensíveis a sais, em particular os de sódio, por serem considerados micronutrientes. Em contrapartida, sais de cálcio, são mais assimiláveis pelas plantas, pois o cálcio é um macronutriente essencial para seu desenvolvimento.

O inconveniente da técnica é que foram descobertos subprodutos provenientes da desinfecção, principalmente nas formas de cloro livre que associados a precursores como os ácidos húmicos, ácidos fúlvicos, brometos ou algas formam diversos compostos clas- sificados como trialometanos (THM).

Os levantamentos epidemiológicos relacionando a concentração dos THM com a morbidade e a mortalidade por câncer não são estatisticamente conclusivos, mas evidenciam associações positivas em alguns casos de carcinomas (MEYER, 1994).

O presente trabalho busca estudar alternativas para uso de efluentes provenientes de estações de tratamento de esgoto na agricultura. Verificou-se que a partir de resultados de parâmetros microbiológicos sugeridos pela legislação brasileira a necessidade de inclusão de uma etapa de desinfecção para que se reduzam as concentrações de coliformes e que sejam atingidas as normas estabelecidas para reúso em culturas agrícolas e padrões de lançamento em corpos receptores de acordo com a OMS (1989) e a CONAMA 357/05.

\section{MATERIAL E MÉTODOS}

O experimento foi realizado no Laboratório de Protótipos Aplicado ao Tratamento de Águas e Efluentes e no Laboratório de Saneamento da Faculdade de Engenharia Civil, Arquitetura e Urbanismo da Universidade Estadual de Campinas - UNICAMP. Utilizou-se esgoto coletado de uma lagoa anaeróbia, denominada Paulistano II, de Franca, São Paulo, administrada pela Concessionária SABESP.

Basicamente, o esgoto proveniente da Lagoa Anaeróbia sofria o tratamento em três células em série compostas por lagoas anaeróbia/facultativa/maturação (sistema Australiano), ao final da lagoa anaeróbia o efluente era coletado.

\section{Características do local de coleta}

A lagoa anaeróbia, denominada Paulistano II, proveniente da Estação de Tratamento de Esgotos administrada pela SABESP da cidade de Franca estado de São Paulo, é operada com tempo de detenção hidráulica de 3,2 dias e recebendo vazão de $17,05 \mathrm{~L} \mathrm{~s}^{-1}$. A cidade de Franca tem cerca de 307.000 habitantes onde 100\% do esgoto produzido é tratado.

A lagoa anaeróbia - Paulistano II - tem todo seu esgoto de origem doméstica. O sistema de tratamento utilizado é composto por três células em série, sendo formado por lagoa anaeróbia, seguida de lagoa facultativa e de maturação. Após o efluente passar por esse sistema de tratamento ele é lançado no córrego Palestina, classificado como classe 2. A figura 1 apresenta uma vista geral da lagoa anaeróbia - Paulistano II. 
Figura 1. Vista geral da lagoa anaeróbia - Paulistano II

Onde: LA - lagoa anaeróbia; LF - lagoa facultativa; LM - lagoa maturação

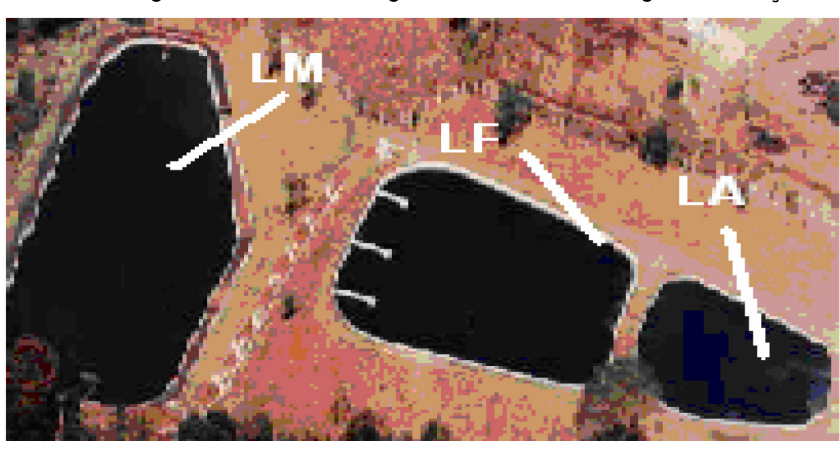

Durante aproximadamente dois meses foram coletadas, semanalmente, amostras do efluente da lagoa anaeróbia e acondicionados em frascos de coleta apropriados para a sua caracterização. Os resultados serão discutidos oportunamente.

\section{Arranjo experimental - Desinfecção Escolha do desinfetante}

Após a caracterização do efluente e a verificação através dos resultados obtidos, verificou-se que o efluente da lagoa anaeróbia poderia sofrer o processo de desinfecção. Com relação a escolha do desinfetante, após alguns estudos realizados no departamento de Saneamento da Unicamp, que já havia testado cloro gasoso, hipoclorito de sódio em solução, radiação ultravioleta e ozônio, além de processos oxidativos avançados, na desinfecção de efluentes domésticos, verificou-se a necessidade de se estudar um reagente de baixo custo, fácil manuseio e que desempenhasse a função de desinfetante deixando um residual de cloro na rede coletora, item este, essencial para atender a norma vigente.

O hipoclorito de cálcio foi escolhido, porque o propósito principal desta pesquisa é aliar o tratamento de efluentes doméstico para uso na agricultura e/ou eventualmente obedecer a padrões de lançamento em corpos receptores.

Com relação à agricultura, o hipoclorito de cálcio, contém íons $\mathrm{Ca}^{+2}$, um macronutriente importante às plantas. Isso não acontece com o hipoclorito de sódio, que contém íons $\mathrm{Na}+\mathrm{l}$ que podem causar impermeabilização dos solos, caso sua concentração seja relativamente alta.

O cálculo utilizado para se obter a massa hipoclorito de cálcio a ser aplicada no efluente da lagoa anaeróbia foram calculadas conforme recomenda a CETESB (2004), veja a equação 1 .

$$
\mathrm{P}=\mathrm{C} . \mathrm{L}
$$

$\%$ B. 10

Onde:

$\mathrm{P}=$ gramas do composto de cloro

$\mathrm{C}=\overline{\mathrm{mg} \mathrm{L}}^{-1}$ de cloro livre desejado na água a ser desinfetada
$\mathrm{L}=$ volume de água a ser desinfetada (L)

$\% \mathrm{~B}=\%$ cloro livre do produto comercial escolhido para emprego.

\section{Desinfecção propriamente dita}

A desinfecção foi efetuada utilizando um equipamento para ensaio de JAR TEST como câmara de contato entre o hipoclorito de cálcio e o efluente. Foi avaliado uma série de parâmetros físicos, químicos e microbiológicos, antes e após a desinfecção: cloro residual livre, total e combinado, $\mathrm{pH}$, temperatura, condutividade, alcalinidade parcial e total, cor aparente e verdadeira, turbidez, nitrato, nitrito, nitrogênio amoniacal e orgânico, DQO bruta e DQO filtrada, fósforo total, OD, sólidos totais, totais fixos e totais voláteis, sólidos suspensos totais, sólidos suspensos fixos e voláteis, além de coliformes totais, E. coli, helmintos e protozoários, parâmetros recomendados por AWWA/ APHA/WEF (2001).

O produto desinfetado foi estudado para ser utilizado para irrigação de uma cultura de milho e, portanto, atender os padrões estabelecidos pela CONAMA 357/05 e pela OMS (1989) para uso em culturas agrícolas e/ou descargas em corpos receptores de classe 2 E.coli $<10^{3} \mathrm{NMP} 100 \mathrm{~mL}^{-1}$ e Helmintos $<1$ ovo $\mathrm{L}^{-1}$.

A desinfecção ocorreu utilizando um equipamento para ensaio de JAR TEST como câmara de contato entre o efluente e o hipoclorito de cálcio. A figura 2 ilustra a desinfecção utilizando o equipamento para ensaio de JAR TEST.

\section{Figura 2. llustração da desinfecção utilizando o equipamento para ensaio de JAR TEST}

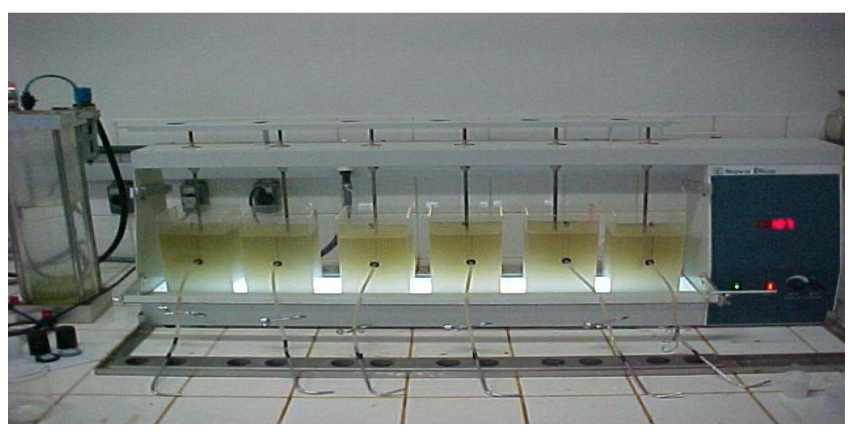

Os parâmetros de processo que foram obedecidos a fim de se obter os resultados propostos no objetivo geral foram:

-Agitação lenta - em torno de 80 - 100rpm;

- Tempo de contato estudado de 30, 45 e 60 minutos;

-Dosagens de hipoclorito de cálcio estudadas para a

Equação 1 lagoa anaeróbia foram: 6, 9, 12, 15, 18, 21, 25, 28 e 32 mg L $L^{-1}$.

\section{Coleta de amostras}

Os frascos utilizados na coleta para análises físico-químicas possui volume de $2 \mathrm{~L}$ (tipo PET) e foram lavados, com ácido clorídrico (1:1),em seguida, foram 
lavados com água destilada, para evitar possíveis contaminações e interferências nos resultados finais, por exemplo na análise de fósforo. Os frascos de coleta utilizados para as amostras microbiológicas foram lavados e autoclavados. Tal procedimento busca a eliminação de microrganismos que podem interferir no resultado final do experimento.

Após a coleta, imediatamente essas amostras foram colocadas no interior de uma caixa de isopor para melhor acondicionamento e para proteção contra radiação ultravioleta. Houve essa preocupação com relação ao recipiente em que os frascos seriam transportados de um laboratório até outro, pois se colocado em recipientes transparentes e sem proteção contra os raios solares o efluente poderia estar sofrendo desinfecção também por radiação ultravioleta, fazendo com que o resultado final fosse comprometido.

\section{Análise estatística dos resultados}

Primeiramente, por se tratar de uma enorme quantidade de dados, foram feitas análises de média de todos os resultados utilizando-se o programa Excel, incluindo a confecção dos gráficos utilizando o mesmo programa.

Os resultados das análises físicas, químicas e microbiológicas foram submetidos a tratamento estatístico fazendo-se uso do programa estatístico SAS (versão 9.1) para interpretação dos dados. Os dados do experimento foram submetidos à análise de variância e as médias comparadas através do teste de Tukey ao nível de $5 \%$.

\section{RESULTADOS E DISCUSSÃO}

A princípio foram realizadas análises para caracterização do efluente proveniente da Lagoa Anaeróbia - Paulistano II. A caracterização foi importante no sentido de se saber as características do esgoto a ser estudado. A tabela 1 apresenta a média dos resultados obtidos durante o período de caracterização da amostra.

Após caracterização da amostra iniciou-se a desinfecção para diferentes dosagens de hipoclorito de cálcio e os resultados sofreram uma série de análises estatísticas para as diversas variáveis estudadas. Como mencionado, utilizou-se o programa estatístico SAS (versão 9.1) para interpretação dos dados. Os dados do experimento foram submetidos à análise de variância e as médias comparadas através do teste de Tukey ao nível de 5\%. A tabela 2 apresenta dados relevantes sobre as análises estatísticas mais especificamente os pvalores. Estudou-se a relação entre as dosagens de hipoclorito de cálcio aplicadas e o tempo de contato entre o efluente e o desinfetante.

Os valores da tabela 2 foram obtidos para cada variável estudada e para cada tratamento (dosagem de hipoclorito de cálcio $\left(\mathrm{mg} \mathrm{L}^{-1}\right)$ e o tempo de contato
Tabela 1 - Caracterização do efluente da Lagoa Anaeróbia Paulistano II

\begin{tabular}{|c|c|}
\hline \multicolumn{2}{|c|}{ Variável analisada } \\
\hline $\mathrm{pH}$ & 7,45 \\
\hline Condutividade & $874\left(\mu \mathrm{S} \mathrm{cm}^{-1}\right)$ \\
\hline Turbidez & 89,3 (UNT) \\
\hline Cor aparente & $760\left(\mathrm{mg} \mathrm{Pt} \mathrm{L}^{-1}\right)$ \\
\hline Cor verdadeira & $154\left(\mathrm{mg} \mathrm{Pt} \mathrm{L}^{-1}\right)$ \\
\hline Alcalinidade parcial & $315,5\left(\mathrm{mg} \mathrm{CaCO}_{3} \mathrm{~L}^{-1}\right)$ \\
\hline Alcalinidade total & $441,7\left(\mathrm{mg} \mathrm{CaCO}_{3} \mathrm{~L}^{-1}\right)$ \\
\hline DQO bruta & $1.333\left(\mathrm{mg} \mathrm{O}_{2} \mathrm{~L}^{-1}\right)$ \\
\hline Nitrato & $4,9\left(\mathrm{mg} \mathrm{L}^{-1}\right)$ \\
\hline Nitrito & $0,0004\left(\mathrm{mg} \mathrm{L}^{-1}\right)$ \\
\hline $\mathrm{N}$ amoniacal & $49,3\left(\mathrm{mg} \mathrm{L}^{-1}\right)$ \\
\hline $\mathrm{N}$ orgânico & $3,15\left(\mathrm{mg} \mathrm{L}^{-1}\right)$ \\
\hline Fósforo Total & $2,35\left(\mathrm{mg} \mathrm{L}^{-1}\right)$ \\
\hline Sólidos Totais (ST) & $925\left(\mathrm{mg} \mathrm{L}^{-1}\right)$ \\
\hline Sólidos Totais Fixos (STF) & $550\left(\mathrm{mg} \mathrm{L}^{-1}\right)$ \\
\hline Sólidos Totais Voláteis (STV) & $375\left(\mathrm{mg} \mathrm{L}^{-1}\right)$ \\
\hline Sólidos Suspensos (SS) & $162\left(\mathrm{mg} \mathrm{L}^{-1}\right)$ \\
\hline Sólidos Suspensos Fixos (SSF) & $80\left(\mathrm{mg} \mathrm{L}^{-1}\right)$ \\
\hline $\begin{array}{c}\text { Sólidos Suspensos Voláteis } \\
\text { (SSV) }\end{array}$ & $82\left(\mathrm{mg} \mathrm{L}^{-1}\right)$ \\
\hline E. coli & $2,00 \cdot 10^{7}\left(\mathrm{NMP} 100 \mathrm{~mL}^{-1}\right)$ \\
\hline Coliformes totais & $3,00 \cdot 10^{7}\left(\mathrm{NMP} 100 \mathrm{~mL}^{-1}\right)$ \\
\hline Helmintos & $9\left(n^{0}\right.$ de indivíduos $\left.L^{-1}\right)$ \\
\hline Protozoários & $7\left(\mathrm{n}^{0}\right.$ de indivíduos $\left.\mathrm{L}^{-1}\right)$ \\
\hline
\end{tabular}

Tabela 2. Dados relevantes sobre as análises estatísticas *Escherichia coli ** Entamoeba coli

\begin{tabular}{|c|c|c|}
\hline \multicolumn{3}{|c|}{$\begin{array}{c}\text { Significância Estatística } \\
\text { Se } p<0,05 \text { então pelo menos duas médias são diferentes }\end{array}$} \\
\hline Variável analisada & $\begin{array}{c}\text { Dosagem de } \\
\text { hipoclorito de cálcio } \\
\left(\mathrm{mg} \mathrm{L}^{-1}\right)\end{array}$ & $\begin{array}{c}\text { Tempo de } \\
\text { Contato (min) }\end{array}$ \\
\hline Cloro Residual Livre & $<0,0001$ & 0,4350 \\
\hline Cloro Residual Total & $<0,0001$ & 0,5424 \\
\hline $\mathrm{pH}$ & $<0,0001$ & 0,0642 \\
\hline Condutividade & $<0,0001$ & 0,4397 \\
\hline Turbidez & 0,1053 & 0,0093 \\
\hline Cor aparente & 0,0008 & 0,0272 \\
\hline Cor verdadeira & $<0,0001$ & 0,1123 \\
\hline Alcalinidade parcial & $<0,0001$ & 0,3401 \\
\hline Alcalinidade total & $<0,0001$ & 0,2826 \\
\hline DQO bruta & 0,0002 & 0,2991 \\
\hline DQO filtrada & 0,0882 & 0,4667 \\
\hline Nitrato & 0,0869 & 0,2468 \\
\hline Nitrito & 0,0160 & 0,1770 \\
\hline $\mathrm{N}$ amoniacal & $<0,0001$ & 0,5105 \\
\hline N orgânico & 0,0041 & 0,1843 \\
\hline Fósforo Total & $<0,0001$ & 0,5679 \\
\hline Sólidos Totais (ST) & $<0,0001$ & 0,0298 \\
\hline Sólidos Totais Fixos (STF) & $<0,0001$ & 0,2549 \\
\hline Sólidos Totais Voláteis (STV) & 0,0724 & 0,0023 \\
\hline Sólidos Suspensos (SS) & 0,0146 & 0,0162 \\
\hline Sólidos Suspensos Fixos (SSF) & 0,2742 & 0,1973 \\
\hline $\begin{array}{l}\text { Sólidos Suspensos Voláteis } \\
\text { (SSV) }\end{array}$ & 0,0019 & 0,0073 \\
\hline E. coli* & $<0,0001$ & 0,3407 \\
\hline Coliformes totais & $<0,0001$ & 0,5876 \\
\hline Cistos de E. coli** & $<0,0001$ & 0,2327 \\
\hline Ovos de Ancilostomatídeos & $<0,0001$ & 0,6016 \\
\hline Larvas de nematóides & $<0,0001$ & 0,0635 \\
\hline
\end{tabular}


(min)), caso os valores obtidos sejam menores que 0,05 significa que as variáveis analisadas dependem ou da dosagem de hipoclorito de cálcio ou do tempo de contato, ou de ambos, ou seja, são dependentes do tratamento. Caso este valor seja superior a 0,05 significa que os fatores do tratamento são independentes, ou seja, a variável analisada não sofre influência do tratamento.

O parâmetro mais relevante para a verificação da eficiência da desinfecção são os dados microbiológicos, mais especificamente, coliformes totais e E. coli, além de ovos de Helmintos. Alguns resultados serão apresentados a seguir.

\section{Coliformes $-E$. coli e totais}

Essa variável é a mais importante no sentido de se saber se a desinfecção foi realmente eficaz e se a dosagem aplicada atingiu os valores recomendados pela CONAMA 357/05 e pela OMS (1989), que diz que para padrões de lançamento em rios de classe 2 quantidade de E. coli não deve ultrapassar 1000 organismos por cada 100 mililitros de amostra, este também é um padrão para reúso em culturas agrícolas. As figuras 3 e 4 apresentam a variação da concentração de E. coli e coliformes totais (NMP $100 \mathrm{~mL}-1$ ) com relação à dosagem de hipoclorito de cálcio (mg L-1) aplicado, respectivamente.

Figura 3. Variação do Log da concentração de E. coli (NMP $100 \mathrm{~mL}-1)$ versus dosagem de hipoclorito de cálcio (mg L-1)

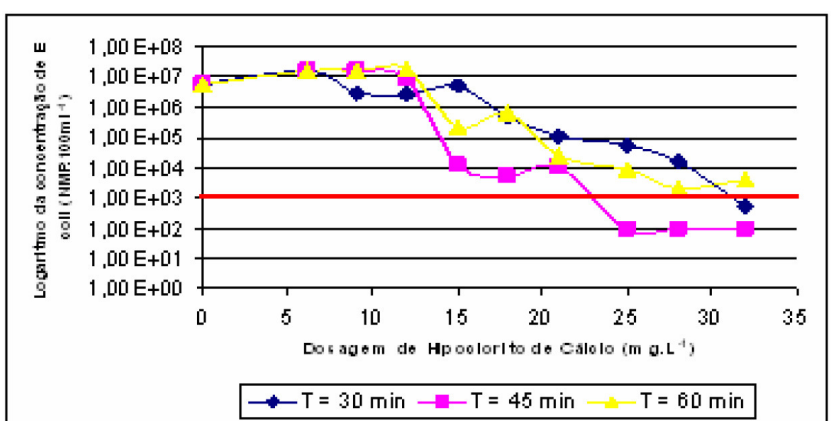

Figura 4. Variação da concentração de Coliformes Totais (NMP $100 \mathrm{~mL}-1$ ) versus dosagem de hipoclorito de cálcio (mg L-1)

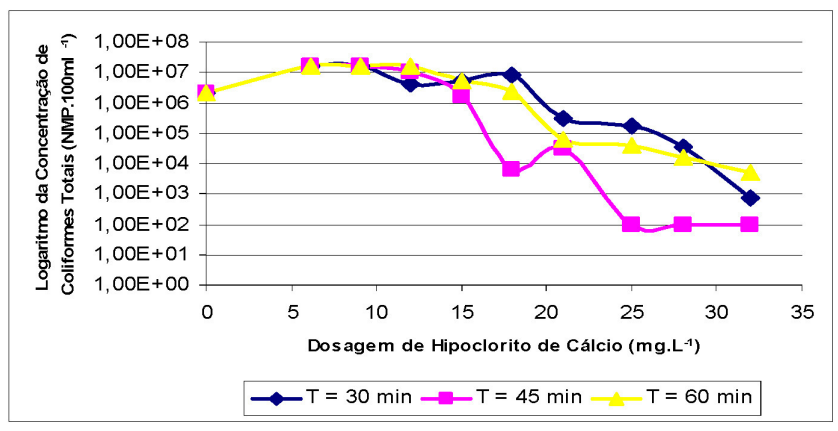

O que pode-se perceber através da figura 3 é que para tempo de contato de 45 minutos o resultado esperado foi alcançado a partir da adição de $25 \mathrm{mg} \mathrm{L}-1$ de hipoclorito de cálcio. Para tempos de contato de 30 e 60 minutos os resultados foram obtidos com dosagens iguais ou superiores a $32 \mathrm{mg} \mathrm{L}-1$ de hipoclorito de cálcio. Nesse caso, é importante salientar que dosagens de hipoclorito de cálcio superiores a $32 \mathrm{mg} \mathrm{L-1}$ não foram testadas por problemas experimentais.

Análises estatísticas foram realizadas e os resultados estão na tabela 3 e 4 que mede a relação entre E. coli e coliformes totais com a dosagem de hipoclorito de cálcio aplicada e o tempo de contato, respectivamente.

Tabela 3. Relação entre o E. coli e coliformes totais e as dosagens de hipoclorito de cálcio aplicado

\begin{tabular}{|c|c|c|c|c|c|}
\hline \multicolumn{3}{|c|}{ Agrupamento Tukey ${ }^{(1)}$} & \multirow{2}{*}{$\begin{array}{l}\text { Médias }^{(2)} \\
1,60 \mathrm{E}+07\end{array}$} & \multirow{2}{*}{$\frac{N^{(3)}}{3}$} & \multirow{2}{*}{ 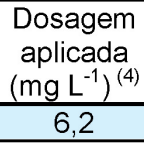 } \\
\hline \multirow{10}{*}{ 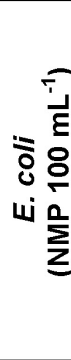 } & $A$ & & & & \\
\hline & $A$ & & $1,12 \mathrm{E}+07$ & 3 & 9,1 \\
\hline & A B & $\mathrm{C}$ & $9,66 E+06$ & 3 & 12 \\
\hline & A $B$ & $\mathrm{C}$ & $6,16 E+06$ & 3 & 0 \\
\hline & $\mathrm{B}$ & $\mathrm{C}$ & $1,74 E+06$ & 3 & 15 \\
\hline & & $\mathrm{C}$ & $3,90 E+05$ & 3 & 18 \\
\hline & & $\mathrm{C}$ & $4,74 E+04$ & 3 & 21 \\
\hline & & $\mathrm{C}$ & $2,04 E+04$ & 3 & 25 \\
\hline & & $\mathrm{C}$ & $6,10 E+03$ & 3 & 28 \\
\hline & & $\mathrm{C}$ & $1,53 E+03$ & 3 & 32 \\
\hline \multirow{10}{*}{ 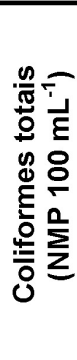 } & $A$ & & $1,60 E+07$ & 3 & 6,2 \\
\hline & $A$ & & $1,60 \mathrm{E}+07$ & 3 & 9,1 \\
\hline & A $\quad$ B & & $1,02 \mathrm{E}+07$ & 3 & 12 \\
\hline & $\mathrm{B}$ & $\mathrm{C}$ & $3,87 E+06$ & 3 & 15 \\
\hline & $\mathrm{B}$ & $\mathrm{C}$ & $3,53 E+06$ & 3 & 18 \\
\hline & & $\mathrm{C}$ & $2,14 \mathrm{E}+06$ & 3 & 0 \\
\hline & & $\mathrm{C}$ & $1,37 E+05$ & 3 & 21 \\
\hline & & $\mathrm{C}$ & $7,06 \mathrm{E}+04$ & 3 & 25 \\
\hline & & $\mathrm{C}$ & $1,76 E+04$ & 3 & 28 \\
\hline & & $\mathrm{C}$ & $1,90 E+03$ & 3 & 32 \\
\hline
\end{tabular}

(1) Significa que os resultados foram agrupados através das letras em maiúsculo; (2) Médias obtidas das análises realizadas; (3) Número de análises realizadas para cada tempo de contato estudado; (4) Dosagem de hipoclorito de cálcio aplicada em $\mathrm{mg} \mathrm{L}^{-1}$ 
Tabela 4. Relação entre o E. coli e coliformes totais e os tempos de contato

\begin{tabular}{|c|c|c|c|c|}
\hline \multicolumn{2}{|c|}{$\underset{(1)}{\operatorname{Aggrupamento} \text { Tukey }}$} & Médias ${ }^{(2)}$ & $\mathbf{N}^{(3)}$ & $\begin{array}{c}\text { Tempo de } \\
\text { contato (min) } \\
(4)\end{array}$ \\
\hline \multirow{3}{*}{ 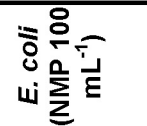 } & $\bar{A}$ & $5,73 E+06$ & 10 & 60 \\
\hline & $A$ & $4,63 E+06$ & 10 & 45 \\
\hline & $\mathrm{A}$ & $3,34 E+06$ & 10 & 30 \\
\hline \multirow{3}{*}{ 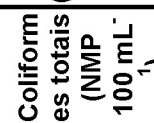 } & $A$ & $5,77 E+06$ & 10 & 60 \\
\hline & A & $5,18 \mathrm{E}+06$ & 10 & 30 \\
\hline & A & $4,63 E+06$ & 10 & 45 \\
\hline
\end{tabular}

(1) Significa que os resultados foram agrupados através das letras em maiúsculo; (2) Médias obtidas das análises realizadas; (3) Número de análises realizadas para cada tempo de contato estudado; (4) Tempo de contato em minutos

Embora os resultados desejados tenham sido obtidos com o tempo de 45 minutos e dosagem acima de $25 \mathrm{mg}$ L-1 de hipoclorito de cálcio visto pela figura 3, as médias para os tempos de contato não se diferem estatisticamente, ou seja, a redução independe do tempo, sendo que a redução dos coliformes está apenas influenciada pela dosagem (25, 28 e 32), embora não atinjam, em média, valores abaixo de 1000 . O que podese ver aqui é uma interação dos fatores, ou seja, os valores de coliforme desejados são conseguidos com tempo de contato 45 minutos e dosagens 25, 28 e 32 .

Portanto, conforme já citado por WHITE (1999) que recomenda tempos superiores a 30 minutos e inferiores a 60 minutos para prevenir a produção de THM's, compostos potencialmente carcinogênicos, tempos de contato de 45 minutos entre o efluente e o desinfetante são efetivos. Com relação às dosagens de hipoclorito de cálcio, a partir de $24 \mathrm{mg}$. L- 1 aplicado foram suficientes para atender a legislação CONAMA 357/05 que sugerem uma quantidade de $\mathrm{E}$. coli menor que 1 .103 NMP. $100 \mathrm{~mL}^{-1}$.

\section{Helmintos e Protozoários}

As análises de helmintos e protozoários foram realizadas nessa pesquisa no sentido de se saber qual é a efetividade do cloro nesses organismos. O que se sabe é que o cloro é muito eficaz na inativação de bactérias e vírus, porém, não é efetivo na inativação de protozoários e helmintos. Os organismos foram identificados com a consulta à literatura especializada. Os resultados foram expressos como número de ovos e/ou larvas de helmintos e cistos de protozoários por 1000 $\mathrm{mL}$. As figuras 5, 6 e 7 apresentam a concentração de Entamoeba. Coli, ovos de Ancilostomatídeos e larvas de nematóides por $1000 \mathrm{~mL}$ com relação à dosagem de hipoclorito de cálcio aplicada, respectivamente.

Foram analisados apenas esses três organismos e análises estatísticas foram realizadas, a tabela 5 e 6 apresentam a relação entre as variáveis: cistos de Entamoeba coli, ovos de Ancilostomatídeos e larvas de
Figura 5. Variação da concentração de cistos de Entamoeba coli em $1000 \mathrm{~mL}^{-1}$ versus dosagem de hipoclorito de cálcio ( $\mathrm{mg}$ $\left.\mathrm{L}^{-1}\right)$

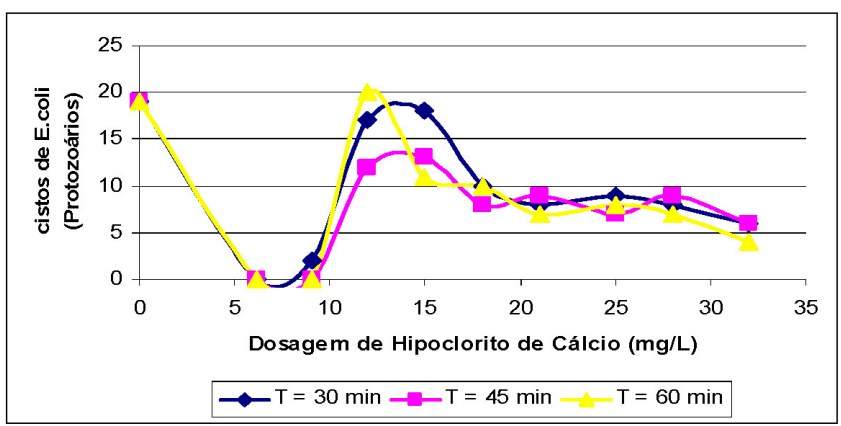

Figura 6. Variação da concentração de ovos de Ancilostomatídeos em $1000 \mathrm{~mL}-1$ versus dosagem de hipoclorito de cálcio (mg L-1)

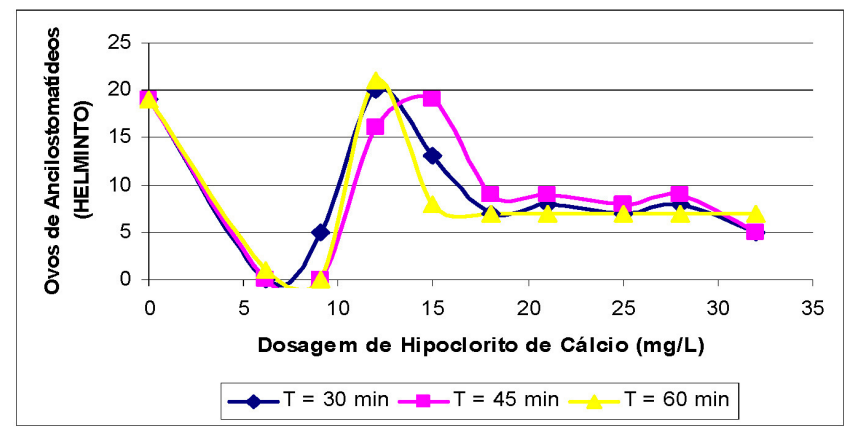

Figura 7. Variação da concentração de larvas de nematóides em $1000 \mathrm{~mL}^{-1}$ versus dosagem de hipoclorito de cálcio ( $\left.\mathrm{mg} \mathrm{L}^{-1}\right)$

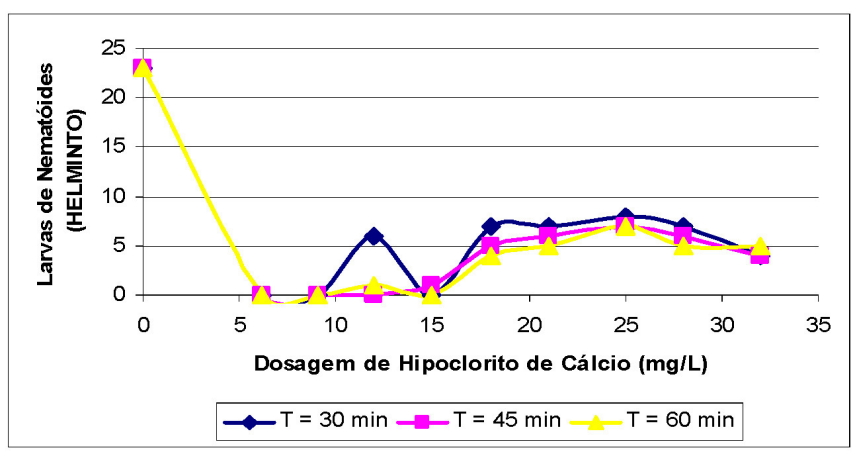


nematóides com relação a dosagem de hipoclorito de cálcio e o tempo de contato aplicado, respectivamente.

Pela análise estatística, o que se percebe é que a quantidade de organismos no efluente bruto, ou seja, sem desinfecção foi a maior encontrada. Porém, em alguns casos, em dosagens de 6,2 e 9,1 mg L-1 foram encontrados a menor quantidade de organismos. O que pode ter acontecido é que a amostra separada para a análise não foi suficiente ou não representativa. Visualmente o que se percebe é que após dosagem de 18 mg L- 1 a quantidade de organismos tanto de helminto quanto de protozoários diminui. Vale ressaltar que a análise foi feita para se saber sobre presença e ausência desses organismos, portanto, estudos mais aprofundados serão necessários pra que se tenham melhores conclusões, pois, de acordo com literatura pesquisada o cloro não tem eficiência nenhuma com relação aos protozoários e helmintos.

Por meio da relação entre as variáveis e o tempo de contato o que se pode concluir que o tempo de contato não é um tratamento influenciável.

\section{CONCLUSÕES}

Foram necessárias dosagens de hipoclorito de cálcio entre 25 e $32 \mathrm{mg}$. L-1 para a adequação do efluente da lagoa anaeróbia ao valor máximo de coliformes totais estabelecido pela OMS (1989) tendo-se em vista o reúso agrícola e, também quanto a CONAMA 357 (2005) para o lançamento em corpos de água receptores.

A eficiência da inativação de coliformes totais e E. coli, não foi influenciada pelo tempo de contato entre o hipoclorito de cálcio e os efluentes, porém ao analisar estatisticamente o tempo de contato de $45 \mathrm{minu}-$ tos, constatou-se que foi aquele que expressou melhores resultados.

Turbidez, cor verdadeira e aparente, revelaram-se como as principais causas pela grande demanda de hipoclorito de cálcio e, a princípio, foi o principal causador na ineficiência da inativação dos microrganismos em dosagens baixas no efluente da lagoa anaeróbia. Isso é importante, mas você não discutiu no corpo do artigo.

O método de Hoffman, Pons e Janer modificado, baseado na contagem de organismos patogênicos em microscópio, não permitiu avaliar a eficiência de desinfecção com hipoclorito de cálcio, em organismos como os helmintos e protozoários. Com relação à remoção de helmintos e protozoários, verificou-se que a cloração não é a técnica mais adequada.

Portanto, conclui-se que dosagens iguais ou superiores a $25 \mathrm{mg}$. L-1 de hipoclorito de cálcio com tempo de contato do desinfetante com o efluente de $45 \mathrm{minu}$ tos são suficientes para a inativação de bactérias do grupo coliformes - E. coli, porém, estudos mais conclusivos com relação a protozoários e helmintos de-
Tabela 6 - Relação entre as variáveis: cistos de Entamoeba coli, ovos de Ancilostomatídeos e larvas de nematóides e os tempos de contato.

\begin{tabular}{|c|c|c|c|c|}
\hline \multicolumn{2}{|c|}{$\underset{(1)}{\operatorname{Agrupamento} \text { Tukey }}$} & \multirow{2}{*}{$\begin{array}{c}\begin{array}{c}\text { Médias } \\
(2)\end{array} \\
10 \\
\end{array}$} & \multirow{2}{*}{$\frac{N^{(3)}}{10}$} & \multirow{2}{*}{$\begin{array}{c}\begin{array}{c}\text { Tempo de } \\
\text { contato (min) } \\
(4)\end{array} \\
30\end{array}$} \\
\hline$\frac{\Phi}{8}=$ & $\bar{A}$ & & & \\
\hline : & A & 9 & 10 & 60 \\
\hline$\frac{\bar{n}}{0}$ & $A$ & 8 & 10 & 45 \\
\hline \multirow{3}{*}{ 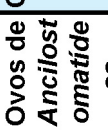 } & $\bar{A}$ & 9 & 10 & 45 \\
\hline & A & 9 & 10 & 30 \\
\hline & $A$ & 8 & 10 & 60 \\
\hline \multirow{3}{*}{ 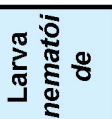 } & $A$ & 6 & 10 & 30 \\
\hline & A & 5 & 10 & 45 \\
\hline & A & 5 & 10 & 60 \\
\hline
\end{tabular}

(1) Significa que os resultados foram agrupados através das letras em maiúsculo; (2) Médias obtidas das análises realizadas; (3) Número de análises realizadas para cada tempo de contato estudado; (4) Tempo de contato em minutos.

Tabela 5. Relação entre as variáveis: cistos de Entamoeba coli, ovos de Ancilostomatídeos e larvas de nematóides e as dosagens de hipoclorito de cálcio aplicado

\begin{tabular}{|c|c|c|c|c|c|c|c|}
\hline \multicolumn{5}{|c|}{ Agrupamento Tukey ${ }^{(1)}$} & Médias (2) & $\mathrm{N}^{(3)}$ & $\begin{array}{l}\text { Dosagem } \\
\text { aplicada } \\
\left(\mathrm{mg} \mathrm{L}^{-1}\right)^{(4)}\end{array}$ \\
\hline \multirow{10}{*}{ 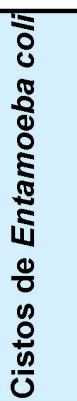 } & \multicolumn{4}{|c|}{$\mathrm{A}$} & 19 & 3 & 0 \\
\hline & \multicolumn{4}{|c|}{$\mathrm{A}$} & 16 & 3 & 12 \\
\hline & $\bar{A}$ & \multicolumn{3}{|l|}{$B$} & 14 & 3 & 15 \\
\hline & & \multicolumn{3}{|c|}{$\mathrm{C}$} & 9 & 3 & 18 \\
\hline & & \multicolumn{3}{|c|}{$\mathrm{C}$} & 8 & 3 & 21 \\
\hline & & \multicolumn{3}{|c|}{$\mathrm{C}$} & 8 & 3 & 25 \\
\hline & & \multicolumn{3}{|c|}{$\mathrm{C}$} & 8 & 3 & 28 \\
\hline & & \multirow{2}{*}{\multicolumn{2}{|c|}{$\mathrm{C}$}} & $\bar{D}$ & 5 & 3 & 32 \\
\hline & & & & $\overline{\mathrm{D}}$ & 0 & 3 & 9,1 \\
\hline & & & & $\bar{D}$ & 0 & 3 & 6,2 \\
\hline \multirow{10}{*}{ 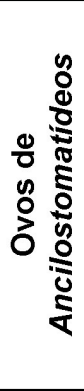 } & \multicolumn{4}{|c|}{ A } & 19 & 3 & 0 \\
\hline & \multicolumn{4}{|c|}{ A } & 19 & 3 & 12 \\
\hline & $\bar{A}$ & \multicolumn{3}{|l|}{$B$} & 13 & 3 & 15 \\
\hline & & \multirow{2}{*}{\multicolumn{3}{|c|}{$\mathrm{C}$}} & 8 & 3 & 21 \\
\hline & & \multicolumn{2}{|r|}{$\mathrm{C}$} & & 8 & 3 & 28 \\
\hline & & \multicolumn{3}{|c|}{ C } & 7 & 3 & 18 \\
\hline & & \multicolumn{3}{|c|}{ C } & 7 & 3 & 25 \\
\hline & & & $C$ & $\bar{D}$ & 5 & 3 & 32 \\
\hline & & \multicolumn{3}{|c|}{$\mathrm{C}$} & 1 & 3 & 9,1 \\
\hline & & & & $\bar{D}$ & 0 & 3 & 6,2 \\
\hline \multirow{10}{*}{ 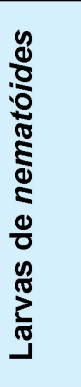 } & $\bar{A}$ & \multirow{2}{*}{\multicolumn{3}{|c|}{$B$}} & 23 & 3 & 0 \\
\hline & & & & & 7 & 3 & 25 \\
\hline & & \multicolumn{3}{|l|}{$\bar{B}$} & 6 & 3 & 28 \\
\hline & & \multicolumn{3}{|l|}{$\frac{B}{B}$} & 6 & 3 & 21 \\
\hline & & $B$ & \multirow{2}{*}{\multicolumn{2}{|c|}{$\frac{c}{C}$}} & 5 & 3 & 18 \\
\hline & & $B$ & & & 4 & 3 & 32 \\
\hline & & \multicolumn{3}{|c|}{$C$} & 2 & 3 & 12 \\
\hline & & & \multicolumn{2}{|c|}{$D$} & 0 & 3 & 15 \\
\hline & & & \multicolumn{2}{|r|}{$\bar{D}$} & 0 & 3 & 6,2 \\
\hline & & & & $\bar{D}$ & 0 & 3 & 9,1 \\
\hline
\end{tabular}

(1) Significa que os resultados foram agrupados através das letras em maiúsculo; (2) Médias obtidas das análises realizadas; (3) Número de análises realizadas para cada dosagem aplicada; (4) Dosagem de hipoclorito de cálcio aplicada em mg L-1. 
vem ser considerados realizados, para que o efluente seja utilizado na agricultura, sem que haja a possibilidade de causar algum dano a saúde da população.

\section{AGRADECIMENTOS}

Agradecimentos especiais à SABESP - Unidade de Franca - SP pelo apoio didático e financeiro $e$ ao CNPq pela concessão da bolsa de mestrado.

\section{REFERÊNCIAS BIBLIOGRÁFICAS}

ANA - Agencia Nacional das Águas. Secretaria de Recursos hídricos. Plano nacional de Recursos hídricos. Documento Base de referencia. Revisão 01, Abril 2003.

AWWA/APHA/WEF. Standard Methods for the Examination of Water and Wastewater. 20.ed. New York: American Public Health Association, 2001.

BRASIL. - Ministério do Meio Ambiente - CONSELHO NACIONAL DO MEIO AMBIENTE (CONAMA). Resolução CONAMA 357/05, de 17/03/2005. Ministério da Saúde.

FAO - Food and Agricultura Organization of the United Nations. http://www.fao.org/, em 15 de out 2002 as 15:30h.

HOTTA, C. Porque não exitem flores no mar? Em Ciência da Vida, jan, 2009. Disponível na World Wide Web: http:/ /scienceblogs.com.br/brontossauros/2009/01/por-que-naoexistem-flores-no-mar.php em 30 de junho 2009.

MEYER, S. T. et al. Chlorine use in water disinfection, trihalomethane formation, and potential risks to public health. Cad. Saúde Pública. [online]. Jan./Mar. 1994, vol.10, no.1, p.99-110. Available from World Wide Web:

http://www.scielo.br/scielo.php?script = sci_arttext\&pid=S0102311X1994000100011\&lng= en\&nrm=iso. Em 30 de maio de 2005.

OMS - ORGANIZAÇÃO MUNDIAL DA SAÚDE . Directrices sanitárias sobre el uso de águas residuales em agricultura e aquicultura. Séries de reportagens técnicas. 778 . OMS, Genebra, 1989.

TOMINAGA, M. Y e MIDIO, A. F. Exposição humana a trialometanos presentes em água tratada. Rev. Saúde Pública. [online]. ago. 1999, vol.33, no.4, p.413-421. Disponível na World Wide Web:

http://www.scielo.br/scielo.php?script $=$ sci_arttext\&pid=S003489101999000400013\&lng = pt\&nrm =iso > Em 02 de junho de2005.

TONON, D. Desinfecção de efluentes sanitários por cloração visando o uso na agricultura. Campinas: Faculdade de Engenharia Civil, Arquitetura e Urbanismo, Universidade Estadual de Campinas, 2007. 284p. Dissertação de mestrado.

WHITE, J. C. "Handbook of chlorination and Alternative Disinfectants". $4^{\mathrm{a}}$ ed. Nova lorque: John Wiley \& Sons, INC. 1999. 1569p. 